\title{
A Simple Straightforward Synthesis of Phenylphosphane and the Photoinitiator Bis(mesitoyl)phenylphosphane Oxide (IRGACURE 819)
}

\author{
Hansjörg Grützmacherª, Jens Geier ${ }^{\mathrm{a}}$, Daniel Stein ${ }^{\mathrm{a}}$, Timo Ottª ${ }^{\mathrm{a}}$, Hartmut Schönberg ${ }^{\mathrm{a}}$, Reinhard
} H. Sommerlade ${ }^{b}$, Souad Boulmaaz ${ }^{b}$, Jean-Pierre Wolf ${ }^{\mathrm{c}}$, Peter Murer ${ }^{\mathrm{c}}$, and Thomas Ulrich ${ }^{\mathrm{d}}$

\begin{abstract}
A straightforward high-yield synthesis for the photoinitiator bis(2,4,6-trimethylbenzoyl)phenylphosphane oxide (16, IRGACURE 819) involves: i) the reaction of phenyldichlorophosphane, $\mathrm{PhPCl}_{2}$, with sodium to give $\left[\mathrm{Na}_{2}\left(\mathrm{P}_{2} \mathrm{Ph}_{2}\right)(\text { tmeda) }]_{6}(\mathbf{5})\right.$; ii) protonation of 5 with tert-butanol to give 1,2-diphenyldiphosphane, PhHP-PHPh (12); iii) reduction of 12 by sodium to yield $[\mathrm{Na}(\mathrm{PHPh})]_{\mathrm{X}}(\mathbf{1 3})$; iv) protonation of 13 with tert-butanol to give phenylphosphane $\mathrm{PhPH}_{2}$ (14) in excellent yields; v) reaction of 14 with 2,4,6-trimethylbenzoylchloride (MesCOCl) in presence of the $\mathrm{NaOt}$-Bu formed in steps ii and iv to give bis(2,4,6-trimethylbenzoyl)phenylphosphane 7; vi) oxygenation of 7 with $30 \%$ aqueous hydrogen peroxide to give the final product 16 . This reaction can be performed in toluene with about $4 \mathrm{vol}-\%$ of tmeda as an activator in a one-pot synthesis without changing the solvent. The structures determined by $\mathrm{X}$-ray diffraction of the unique hexameric aggregate 5 and $\mathbf{1 6}$ are reported.
\end{abstract}

Keywords: Acylphosphanes · Ion triples · Phosphanes · Phosphorus · Photoinitiators · Sodium

\section{Introduction}

Bis(acyl)phosphanoxides (BAPOs) are very potent photoinitiators for a wide variety of polymerization, coating, and curing processes and have been intensively investigated over the last two decades.[1] Commonly they are synthesized from a primary phosphane and two equivalents of

Correspondence: Prof. Dr. H. Grützmachera Tel.: +411632 2855

Fax: +4116331032

E-mail: hgruetzmacher@ethz.ch

aDepartment of Chemistry and Applied Biosciences

ETH Zürich, Wolfgang-Pauli-Strasse 10

$\mathrm{CH}-8093$ Zürich

bProcess Research, Coating Effects Segment

Ciba Inc., P.O. Box, CH-4002 Basel

'R\&D, Coating Effects Segment, Ciba Inc., P.O. Box

$\mathrm{CH}-4002$ Basel

dProcess Optimization, Coating Effects Segment

Ciba Inc., P.O. Box, CH-4002 Base acylchloride in presence of a base which leads to bis(acyl)phosphanes (BAPs) in the first step (Eqn. (1), Scheme 1). Oxidation with hydrogen peroxide subsequently leads to the corresponding BAPO. However, due to its pyrophoric and toxic properties, phenylphosphane is no longer available in bulk quantities. Alternatively, the reaction of bismetallated phosphandiides, $\left[\mathrm{M}_{2} \mathrm{PR}\right]$, with acylchlorides was proposed (Eqn. (2)). The ' $\mathrm{M}_{2} \mathrm{PR}$ ' compounds were believed to be formed in the reaction of organyl phosphorus dichlorides, $\mathrm{RPCl}_{2}$, with alkali metals $\mathrm{M}$ $=\mathrm{Li}, \mathrm{Na}, \mathrm{K}$. Specifically, the commercially available bis(2,4,6-trimethylbenzoyl)phenylphosphane oxide IRGACURE 819 has been prepared from $\mathrm{PhPCl}_{2}$, lithium, and 2,4,6-trimethylbenzoylchloride (MesCO-

$\mathrm{Cl}$ ) in THF as solvent (Scheme 1). ${ }^{[2]}$ Disad- vantages in this preparation are the use of lithium as reducing metal and the necessity to change the solvent before the oxygenation with $\mathrm{H}_{2} \mathrm{O}_{2}$.

Hence, the development of a protocol for the synthesis of IRGACURE 819 in hydrocarbon solvents and employing sodium as a cheaper reducing metal was desirable. With this aim in mind, we started to investigate the reaction of phenyldichlorophosphane, $\mathrm{PhPCl}_{2}$ (IUPAC: phenylphosphonous acid dichloride) with sodium in toluene or xylene in the presence of small amounts of tetramethylethylenediamine, tmeda, as an activator. In this report, we describe the tmeda complex of disodium diphenyldiphosphandiide, $\left[\mathrm{Na}_{2}\left(\mathrm{P}_{2} \mathrm{Ph}_{2}\right)(\text { tmeda })\right]_{6}$, whose structure we finally could determine, and a convenient one-pot synthesis of IRGACURE

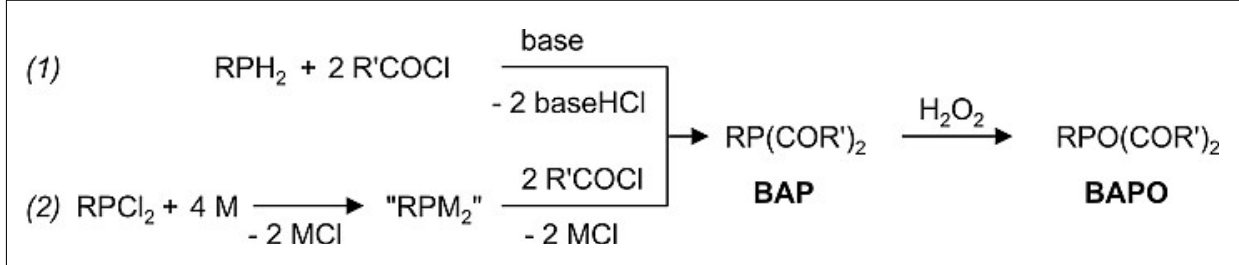


819 from $\mathrm{PhPCl}_{2}$, sodium, and $\mathrm{MesCOCl}$ in a hydrocarbon solvent.

\section{Results and Discussion}

In the first steps of the reaction of $\mathrm{PhPCl}_{2}$ with sodium, the cyclic pentaphenylcyclopentaphosphane, $(\mathrm{PhP})_{5}$, is obtained in reductive bond-forming reactions without the detection of any other intermediates. ${ }^{[3]}$

In the following steps, $\mathrm{P}-\mathrm{P}$ bonds are reductively cleaved (a reaction typical for compounds containing bonds between heavier main group elements, c.f. sulfur, silanes, etc.) and depending on the reaction conditions the 1,2,3,4-tetraphenyltetraphosphane-1,4-diide, $\left.\left[\mathrm{Na}_{2}\left(\mathrm{P}_{4} \mathrm{Ph}_{4}\right) \text { (tmeda }\right)_{2}\right]$ (3), ${ }^{[4]}$ 1,2,3-triphenyltriphosphane-1,3-diide, $\left[\mathrm{Na}_{2}\left(\mathrm{P}_{3} \mathrm{Ph}_{3}\right)(\text { tmeda })_{3}\right](4),{ }^{[4]}$ or 1,2-diphenyldiphosphan-1,2-diide $\left[\mathrm{Na}_{2}\left(\mathrm{P}_{2} \mathrm{Ph}_{2}\right) \text { (tmeda) }\right]_{6}$ (5) were obtained (Scheme 2). In Fig. 1, simplified sketches of the structures of $\mathbf{3}$ and 4 and the dimethoxyethane (dme) solvate $\left[\mathrm{Na}(\text { dme })_{3}\right]^{+}\left[\mathrm{Na}\left(\mathrm{P}_{2} \mathrm{Ph}_{2}\right)(\text { dme })_{3}\right]^{-}$, which was obtained previously by crystallization from dme, ${ }^{[4]}$ are displayed $(\bullet=\mathrm{P}, \oplus=\mathrm{Na}, \mathrm{O}=\mathrm{C})$. Especially tetraphosphandiides, $\left[\mathrm{M}_{2}\left(\mathrm{P}_{4} \mathrm{Ph}_{4}\right)\right.$ $(\text { solv })_{\mathrm{x}}$ ], were intensively investigated and a number of X-ray diffraction studies were performed to elucidate their structures. ${ }^{[5]}$

Due to dynamic processes and the fact that relatively small changes in their conformations provoke large variations in the ${ }^{31} \mathrm{P},{ }^{31} \mathrm{P}$ coupling constants, the ${ }^{31} \mathrm{P}$ NMR spectra of $\mathrm{M}_{2}\left(\mathrm{P}_{4} \mathrm{R}_{4}\right)$ species in solution are complicated and ill-defined very broad resonances at room temperature are frequently observed. ${ }^{[6,7]}$ However, these data allowed us to identify the yellow almost insoluble compound obtained in the reaction between $(\mathrm{PhP})_{5}\left(\right.$ or $\left.\mathrm{PhPCl}_{2}\right)$ with sodium in toluene or xylene in the absence of tmeda as the almost solvent-free tetraphosphandiide, $\left[\mathrm{Na}_{2}\left(\mathrm{P}_{4} \mathrm{Ph}_{4}\right)\right]_{\mathrm{x}}\left(\mathbf{3}^{\prime}\right)$. This compound is not further degraded to smaller dianions in the absence of additives like tmeda. The triphosphandiide $\left[\mathrm{Na}_{2}\left(\mathrm{P}_{3} \mathrm{Ph}_{3}\right)(\text { tmeda })_{3}\right]$ (4) is a rare example of a structurally characterized compound. ${ }^{[8]}$ Remarkably, $\mathbf{4}$ is not formed by reductive degradation of the tetraphosphandiide $\left[\mathrm{Na}_{2}\left(\mathrm{P}_{4} \mathrm{Ph}_{4}\right)(\text { tmeda })_{2}\right]$ (3) but by a synproportionation reaction between 3 and $\left[\mathrm{Na}_{2}\left(\mathrm{P}_{2} \mathrm{Ph}_{2}\right)(\text { tmeda })\right]_{6} \cdot{ }^{[5 \mathrm{~d}]}$ Note that we were not able to detect any species which may be formulated as $\left[\mathrm{Na}_{2} \mathrm{PPh}\right]$ under any of our reaction conditions (hydrocarbon/tmeda solvents, $\mathrm{T}$ up to $140{ }^{\circ} \mathrm{C}$ ).

The dme solvate $\left[\mathrm{Na}(\mathrm{dme})_{3}\right]^{+}\left[\mathrm{Na}_{5}\right.$ $\left.\left(\mathrm{P}_{2} \mathrm{Ph}_{2}\right)_{3}(\mathrm{dme})_{3}\right]^{-}$(see Fig. 1C) ${ }^{[5 \mathrm{a}]}$ and $\left[\mathrm{Li}_{2}\left(\mathrm{P}_{2} \mathrm{Ph}_{2}\right)(\text { tmeda })_{2}\right]^{[6]}$ are the only compounds known to date which contain the vicinal dianion $\left[\mathrm{P}_{2} \mathrm{Ph}_{2}\right]^{2-}$. We were now able to determine the structure of the tmeda complex 5 by an X-ray diffraction study. This shows $\mathbf{5}$ to be a hexameric ionic aggregate with a unique structure (Fig. 2).

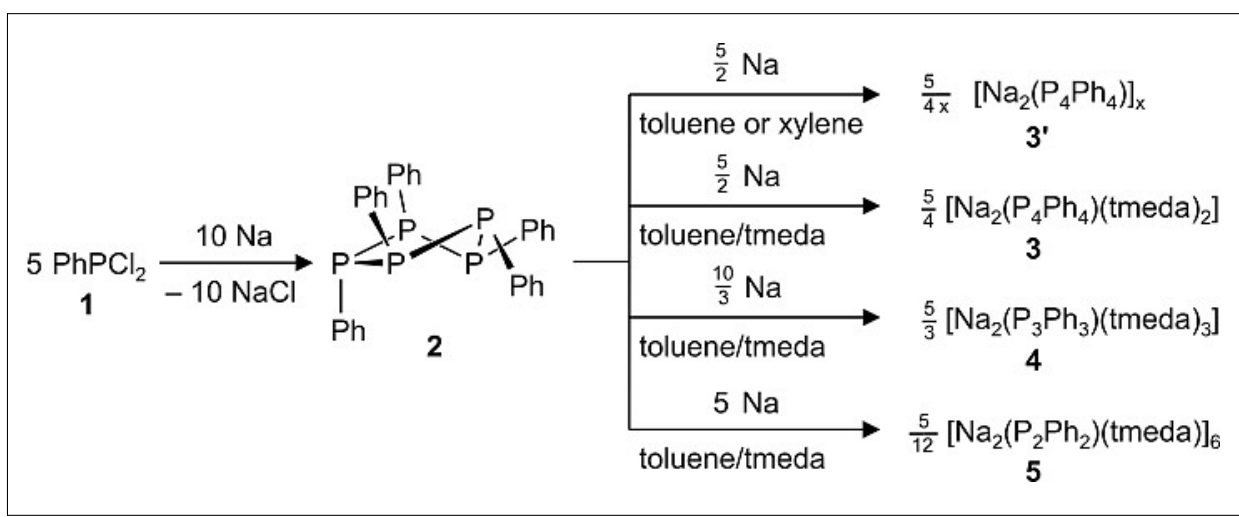

Scheme 2. Synthesis of disodium oligo(phenyl)phosphandiides 3-5 in hydrocarbon solvents
A)

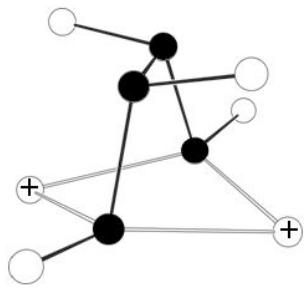

$\left[\mathrm{Na}_{2}\left(\mathrm{P}_{4} \mathrm{Ph}_{4}\right)(\text { tmeda })_{2}\right]$
B)

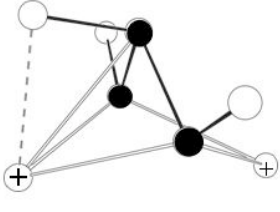

$\left[\mathrm{Na}_{2}\left(\mathrm{P}_{3} \mathrm{Ph}_{3}\right)(\text { tmeda })_{3}\right]$

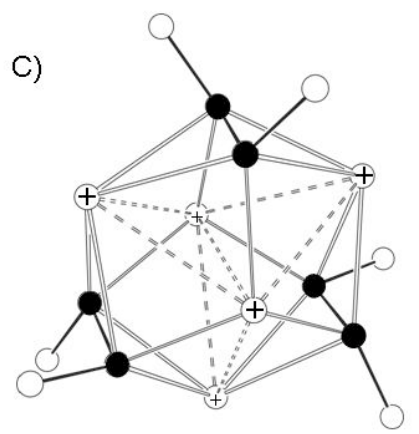

$\left[\mathrm{Na}(\mathrm{dme})_{3}\right]^{+}\left[\mathrm{Na}_{5}\left(\mathrm{P}_{2} \mathrm{Ph}_{2}\right)_{3}(\mathrm{dme})_{3}\right]^{-}$
Fig. 1. Schematic representations of $\left[\mathrm{Na}_{2}\left(\mathrm{P}_{4} \mathrm{Ph}_{4}\right)(\mathrm{tmeda})_{2}\right]$ (3), $\left[\mathrm{Na}_{2}\left(\mathrm{P}_{3} \mathrm{Ph}_{3}\right)(\mathrm{tmeda})_{3}\right]$ (4), and $\left[\mathrm{Na}(\mathrm{dme})_{3}\right]^{+}\left[\mathrm{Na}_{5}\left(\mathrm{P}_{2} \mathrm{Ph}_{2}\right)_{3}(\mathrm{dme})_{3}\right]^{-}$highlighting the core-structures composed from the $\mathrm{P}$ atoms $(\cdot)$, the sodium cations $(\Theta)$ and ipso-carbons of the phenyl rings $(O)$.

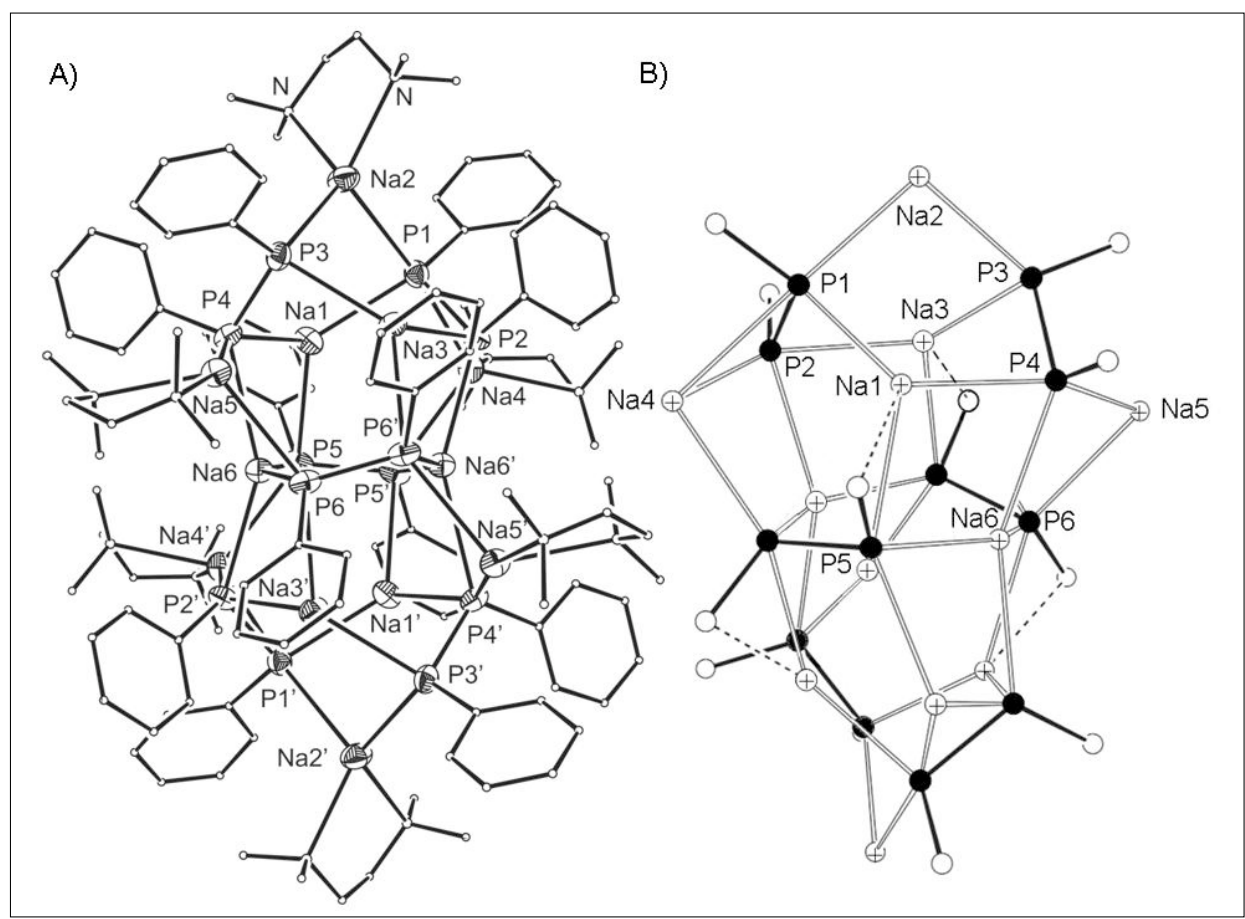

Fig. 2. Structure of $\left[\mathrm{Na}_{2}\left(\mathrm{P}_{2} \mathrm{Ph}_{2}\right)(\mathrm{tmeda})\right]_{6}$ (5). A) Hydrogen atoms are omitted for clarity. B) Schematic representation of 5 highlighting the core structure composed from the $P$ atoms $(\cdot)$, the sodium cations $(\oplus)$ and ipso-carbons of the phenyl rings $(O)$. Selected bond lengths $[\AA]$ and angles $\left[^{\circ}\right]$ : Na1-P1 2.796(4), Na1-P4 2.939(4), Na1-P5 2.911(4), Na2-P1 2.870(4), Na2-P3 2.852(4), Na3-P3 2.837(4), Na3-P2 2.965(4), Na3-P6' 2.920(4), Na4-P1 3.043(4), Na4-P2 2.911(4), Na4-P5' 2.974(4), Na5-P4 2.970(4), Na5-P6 2.998(4), Na6-P2' 2.935(4), Na6--P4 3.013(4), Na6-P6 2.927(4), Na6-P5 2.982(4),

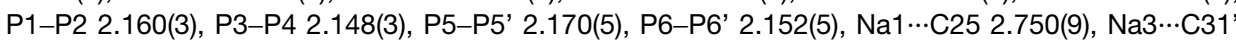
2.804(8), C1-P1-P2-C7 71.5(4), C13-P3-P4-C19 74.2(4), C25-P5-P5'-C25' -92.3(6), C31-P6P6'-C31' -86.6(5). 
In this $C_{2}$-symmetric species, only six of the twelve sodium cations ( $\mathrm{Na} 2, \mathrm{Na} 4, \mathrm{Na} 5$ and their symmetry equivalents) are coordinated to tmeda molecules. $\mathrm{Na} 2$ and $\mathrm{Na} 5$ reside in slightly distorted tetrahedral coordination spheres (two nitrogen, two phosphorus centers) while $\mathrm{Na} 4$ is pentacoordinated to three phosphorus atoms and one tmeda molecule. The other sodium cations, Na1, $\mathrm{Na} 3$, and $\mathrm{Na} 6$, are tmeda free. The $\mathrm{Na} 1$ and $\mathrm{Na} 3$ ions are coordinated to three phosphorus centers and show an additional long contact (2.750 $\AA$ and $2.804 \AA$, respectively) to one ipso-carbon of an adjacent phenyl group (see dotted lines in Fig. 2B). Na6 resides in a strongly flattened tetrahedral coordination sphere spanned by four $\mathrm{P}$ atoms. The $\mathrm{Na}-\mathrm{P}$ distances $(2.796-3.043 \AA)$ lie within the usual range (for a listing see ref. [6]). The $\mathrm{P}-\mathrm{P}$ bond distances $(2.148-2.170 \AA)$ in the $\left[\mathrm{Ph}_{2} \mathrm{P}_{2}\right]^{2-}$ dianions which all have a gauche conformation (IC-P-P-Cl 71.5-92.3 ${ }^{\circ}$ ) are remarkably short compared to the previously reported values $(>2.2 \AA) .{ }^{[5 a, 6]}$ The aggregate 5 is the first we observe that is not composed from $\left\{\left(\mathrm{Na}^{+}\right)_{2}\left(\mathrm{P}_{\mathrm{x}} \mathrm{Ph}_{\mathrm{x}}\right)^{2-}\right\}$ ion triples. In such an ion triple, the $\mathrm{Na}^{+}$cations bridge the negatively charged phosphorus atoms in form of a (flat or modestly folded) parallelogram which is an especially stable arrangement for electrostatic reasons (see discussion in ref.[6]). In 5, only the sodium cation $\mathrm{Na} 4$ resides in such a bridging position over one $\left[\mathrm{P}_{2} \mathrm{Ph}_{2}\right]^{2-}$ dianion, all other sodium cations take bridging positions between different $\left[\mathrm{P}_{2} \mathrm{Ph}_{2}\right]^{2-}$ dianions. We assume that the increased steric bulk of the tmeda as coligand $^{[9]}$ is responsible for the formation of a larger cluster than with dme. The steric encumbrance lowers the coordination enthalpies of the sodium cations which in turn search additional (longer) contacts to phosphorus or carbon centers whereby the aggregation state increases. It is likely that larger aggregates are generally observed with the heavier alkali cations $\left(\mathrm{M}^{+}=\mathrm{Na}^{+}-\mathrm{Cs}^{+}\right)$and diphosphandiides as counter-dianions. In the corresponding lithium compounds, the $\mathrm{Li}^{+}, \mathrm{P}^{-}$distances are short $(\approx 2.6 \AA)$ which gives rise to a sufficiently high electrostatic stabilization energy (ESP) even in a simple archetypical ion triple as $\left[\mathrm{Li}_{2}\left(\mathrm{P}_{2} \mathrm{Ph}_{2}\right)(\right.$ tmeda) $\left.{ }_{2}\right]$. ${ }^{[6]}$

In aggregates with $\mathrm{M}=\mathrm{Na}-\mathrm{Cs}$, the longer $\mathrm{M}^{+}, \mathrm{P}^{-}$contacts do not sufficiently stabilize a small aggregate which is relatively more destabilized especially by the repulsive $\mathrm{P}^{-}, \mathrm{P}^{-}$interaction. Note that the number of attractive $\mathrm{M}^{+}, \mathrm{P}^{-}$contacts per additional incorporation of a $\mathrm{M}_{2}\left(\mathrm{P}_{2} \mathrm{Ph}_{2}\right)$ unit increases more rapidly than the repulsive $\mathrm{M}^{+}, \mathrm{M}^{+}$, and $\mathrm{P}^{-}, \mathrm{P}^{-}$interactions (the exact ratio depends on the structural details $\left.{ }^{[6]}\right)$.

When 5 is reacted with $\mathrm{MesCOCl}(\mathbf{6})$, a $50 \%$ yield of the BAP compound 7 is obtained and not the expected bis(acyl) diphosphane, (MesCO)PhP-PPh(COMes).

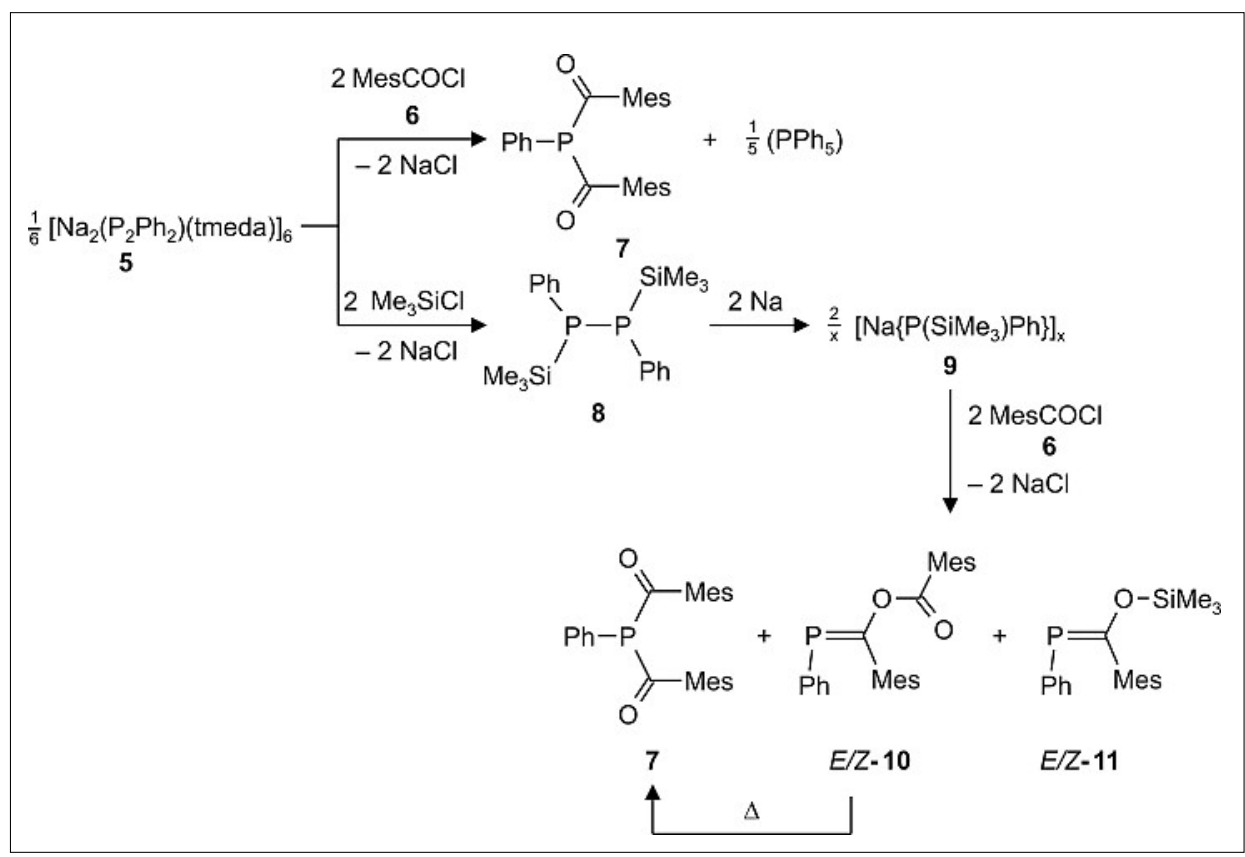

Scheme 3. Reactions of 5 with 2,4,6-trimethylbenzoylchloride (MesCOCl) 6 and $\mathrm{Me}_{3} \mathrm{SiCl}$ and synthesis of BAP 7

Obviously, the monoacylated product, [(MesCO)PhP-PPh $]^{-}$undergoes a fast fragmentation into the phospha-enolate $[\mathrm{PhP}=\mathrm{CO}(\mathrm{Mes})]^{-}$which is immediately intercepted by a second equivalent of the acid chloride $\mathbf{6}$. The other product of this fragmentation, phenylphosphinidene $\mathrm{PhP}$, immediately oligomerizes to $(\mathrm{PhP})_{5}$ which is the other observed species (Scheme 3).

On the other hand, trimethylsilylchloride as electrophile reacts cleanly with $\mathbf{5}$ to yield the expected 1,2-diphenyl-1,2-disilyldiphosphane 8 $\left({ }^{31} \mathrm{PNMR}: \delta=-108 \mathrm{ppm}^{[10]}\right)$. The P-P bond in $\mathbf{8}$ is easily reductively cleaved by sodium in toluene and gives the soluble monosilylated phenylphosphanide sodium salt 9 (aggregation state $\mathrm{x}$ unknown) $\left({ }^{31} \mathrm{P}\right.$ NMR: $\left.\delta=-156 \mathrm{ppm}^{[11]}\right)$. Without isolation, 9 was further reacted with $\mathrm{MesCOCl}$ to give the desired bis(acyl)phosphane $\mathbf{7}$ as the main product. Further by-products are the phosphaenols $\mathbf{1 0}$ and 11, which were obtained as $E$ - and $Z$ - isomers and identified by their typical ${ }^{31} \mathrm{P}$ NMR chemical shifts $(E-10: \delta=196.0$ ppm, $Z-10: \delta=189$ ppm; $E-11: \delta=149$ ppm, $Z-11: \delta=134$ ppm $\left.^{[12]}\right)$. The O-acyl phosphaenols E/Z-10 undergo a remarkable 1,2-acyl shift reaction to BAP 7 upon warming in toluene, however, the O-silyl enolates E/Z-11 cannot be further converted to 7 even at elevated temperature and excess of $\mathrm{MesCOCl}$. Because the content of E/Z-11 amounts to about 15-20\% of the product and furthermore $\mathrm{Me}_{3} \mathrm{SiCl}$ is needed, this process for the preparation of 7 was abandoned.

Brandsma et al. published a series of papers describing the synthesis of alkali metal phosphides, $\left[\mathrm{M}\left(\mathrm{PH}_{2}\right)\right]$, from elemental phosphorus or $\mathrm{PCl}_{3}$ and lithium or sodium metal in liquid ammonia in the presence of tertbutanol as proton source. ${ }^{[13]} \mathrm{We}$ wondered whether the addition of tert-butanol under our reaction conditions would likewise allow the in situ preparation of phenylphosphane 14. To test this hypothesis, we reacted the disodium diphosphanediide $\mathbf{5}$ with two equiv. of tert-butanol which cleanly led to the diphosphane $12\left({ }^{31} \mathrm{P}\right.$ NMR: $\delta=-68$ and $-72 \mathrm{ppm}$ for the meso- and rac-form, respectively ${ }^{[14]}$ ) (Scheme 4). At $\mathrm{T}=100{ }^{\circ} \mathrm{C}$, 12 reacts quantitatively with sodium metal to give sodium(phenylphosphide) $13\left({ }^{31} \mathrm{P}\right.$ NMR: $\delta=-121 \mathrm{ppm}^{[15])}$, which is protonated by another two equiv. of tert-butanol to give phenylphosphane in almost quantitative yield ( ${ }^{31} \mathrm{P}$ NMR: $\delta=-123 \mathrm{ppm}$, triplet, ${ }^{1} J_{\mathrm{PH}}$ $\left.=197.4 \mathrm{~Hz})^{[16]}\right)$. Only traces $(<3 \%)$ of the monosodium salt $\left[\mathrm{Na}\left(\mathrm{P}_{2} \mathrm{Ph}_{2} \mathrm{H}\right)(\text { solv })\right]_{x} \quad 15$ are observed.[17]

When $\mathrm{MesCOCl}$ is added slowly to this reaction mixture and the temperature is kept below $70{ }^{\circ} \mathrm{C}$ an almost quantitative yield of BAP 7 is obtained. Note that the reaction mixture contains exactly the amount of $\mathrm{NaO} t \mathrm{Bu}$ needed as base to promote the reaction between $\mathrm{PhPH}_{2} 14$ and the sterically congested $\mathrm{MesCOCl} \mathbf{6}$. Weaker bases like $\mathrm{NEt}_{3}$ are ineffective. Because the reaction of $t-\mathrm{BuOH}$ with sodium is slower than the reductive cleavage of the $\mathrm{P}-\mathrm{P}$ bond in $\mathbf{1 2}$ even at elevated temperatures, the synthesis of BAP 7 can be performed as a one-pot procedure: $\mathrm{PhPCl}_{2}$ is reacted with four equiv. of sodium in a toluene/tmeda mixture (100/4 by volume) at $\mathrm{T}=120{ }^{\circ} \mathrm{C}$ until 5 precipitates as bright yellow powder. Subsequently, two equivalents $\mathrm{t}-\mathrm{BuOH}$ are added, the reaction kept at $120{ }^{\circ} \mathrm{C}$ until the remaining sodium completely dissolved, and addition 


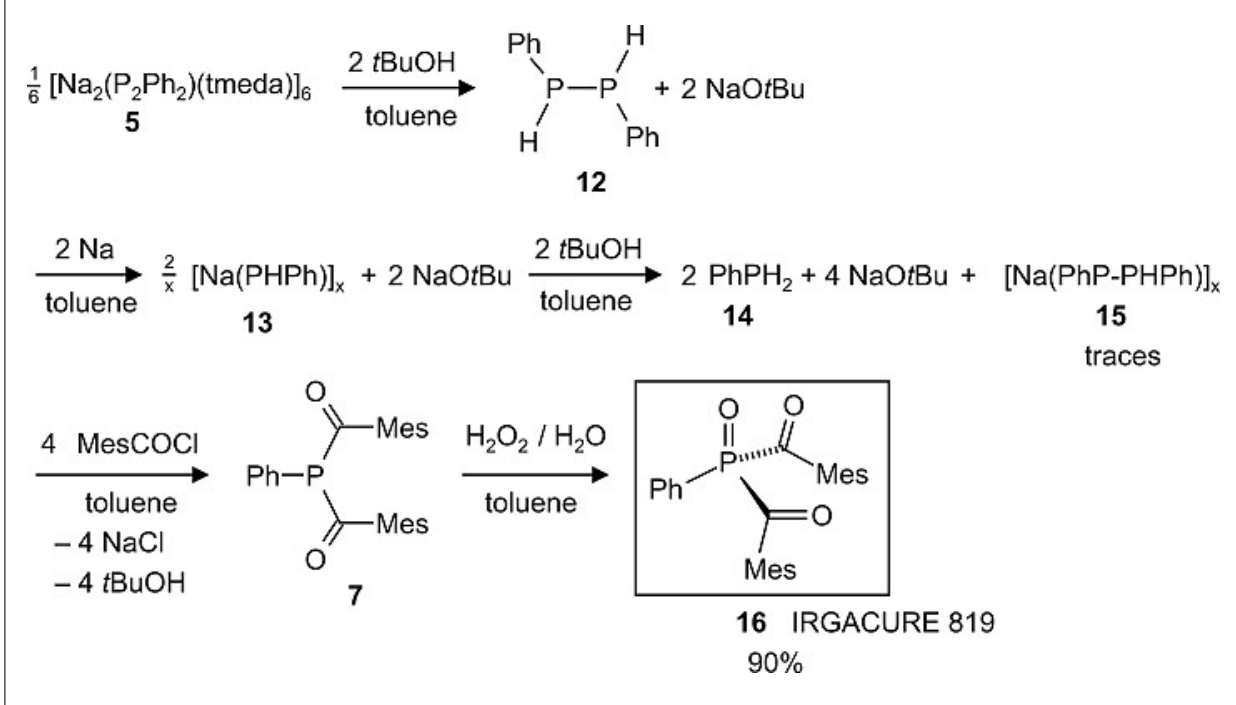

Scheme 4. Efficient synthesis of phenylphosphane $\mathbf{1 4}$ and the bis(acyl)phosphane oxide IRGACURE 819 (16)

of $\mathrm{MesCOCl}$ discloses the synthesis ( $>90 \%$ yield of 7). Subsequently, the added tmeda is neutralized with a stoichiometric amount of conc. $\mathrm{H}_{2} \mathrm{SO}_{4}$ acid before $30 \%$ aqueous $\mathrm{H}_{2} \mathrm{O}_{2}$ is added ( 3 equiv.) at $40-50{ }^{\circ} \mathrm{C}$ to oxygenate BAP 7 to the final product IRGACURE 819 (16). Under optimized conditions, overall yields as high as $90 \%$ can be obtained.

\section{Structure Determination of IRGACURE 819 (16)}

To our knowledge, no X-ray diffraction study has been performed to elucidate the structure of a bis(acyl)phosphane or bis(acyl)phosphane oxide derivative. The structures of several mono(acyl) substituted phosphorus compounds are known. ${ }^{[17]} \mathrm{We}$ have performed an X-ray diffraction study with a crystal of $\mathbf{1 6}$ grown from a saturated toluene solution. A plot of the structure is given in Fig. 3, selected bond lengths and angles are given in the Fig. legend.

Of interest are the phosphorus acyl carbon bond lengths, $\mathrm{P} 1-\mathrm{C} 7$ and $\mathrm{P} 1-\mathrm{C} 17$, which are broken in the photolytic process. ${ }^{[1 \mathrm{a}-\mathrm{h}]}$ These bonds in $\mathbf{1 6}$ are indeed remarkably long (1.895(3)/1.896(3) ̊) especially when compared to the distance between P1 and the ipso-carbon atom $\mathrm{C} 1$ of the phenyl group, which is likewise $\mathrm{sp}^{2}$ hybridized: the $\mathrm{P} 1-\mathrm{C} 1$ bond $(1.797(3) \AA)$ is about $0.1 \AA$ shorter and in the expected range. In other monoacylphosphane oxides the corresponding $\mathrm{P}-\mathrm{C}_{\mathrm{acyl}}$ bonds $\left(1.808-1.872 \AA^{[17]}\right)$ are also elongated but slightly shorter than in $\mathbf{1 6}$. The CO-PO-CO chromophore in $\mathbf{1 6}$ has a syn,anti-conformation, i.e. the $\mathrm{C} 7=\mathrm{O} 2$ group points to the same side as the $\mathrm{P} 1=\mathrm{O} 1$ bond (torsion angle $63.9^{\circ}$ ) while the $\mathrm{C} 17=\mathrm{O} 3$ group points to the opposite side (torsion angle $\left.-174.4^{\circ}\right)$. It remains to be seen, in how far these ground state properties, i.e.

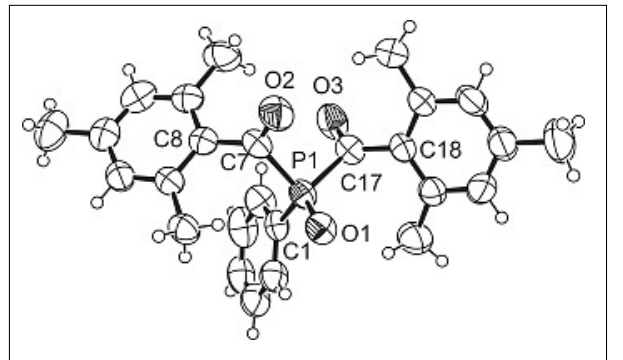

Fig. 3. Structure of $\mathrm{PhPO}(\mathrm{COMes})_{2} \quad$ (16). Selected bond lengths $[\AA \AA]$ and angles [ $\left.{ }^{\circ}\right]: \mathrm{P} 1-01$ 1.475(2), P1-C1 1.797(3), P1-C7 1.895(3), $\mathrm{P} 1-\mathrm{C} 17$ 1.896(3), C7-02 1.210(3), C17-O3 1.226(3), C7-C8 1.491(4), C17-C18 1.487(4), O1-P1-C1 114.7(2), O1-P1-C7 111.9(1), O1-P1 C17 116.3(1), C1-P1-C7 110.1(1), C1-P1-C17 105.9(1), C7-P1-C17 96.3(1), O2-C7-P1-O1 63.9(1), O3-C17-P1-O1-174.4(1).

the lengthening of the $\mathrm{P}-\mathrm{C}_{\mathrm{acyl}}$ bonds and the special arrangement of the CO-PO-CO chromophore, relate to the efficiency by which the reactive excited triplet state is populated and decays in an $\alpha$-cleavage reaction.

In summary, a straightforward one-pot synthesis of bis(2,4,6-trimethylbenzoyl) phenyl phosphane oxide 16, the commercial photoinitiator IRGACURE ${ }^{\circledR} 819^{\mathrm{TM}}$, could be developed. The new protocol avoids the use of ethereal solvents and employs sodito lithium. Furthermore, the yield could be improved significantly. The detailed knowledge of the molecular components like the hexameric ion aggregate $\left[\mathrm{Na}_{2}\left(\mathrm{P}_{2} \mathrm{Ph}_{2}\right)\right.$ (tmeda) $]_{6}(5)$ which are encountered along the complex reaction path when $\mathrm{PhPCl}_{2}$ reacts with sodium in consecutive reductive bond

\section{Conclusion} um as metal of lower ecotoxicity compared forming and cleavage reactions, served as basis for the successful development of a new more environmentally friendly IRGACURE synthesis. We are currently extending the synthetic method reported here to the preparation of a broader range of BAPO type photoinitiators.

\section{Experimental Part}

\subsection{General Techniques}

All syntheses were performed in flamedried glassware under an atmosphere of argon using standard Schlenk techniques. Toluene or xylene was freshly distilled from sodium/tetraglyme/benzophenone and tmeda was dried over calcium hydride prior to use. Air-sensitive compounds were stored and weighed in an argon filled glove box (Braun MB 150 B-G system) and reactions on small scale were performed directly in the glove box.

NMR spectra were recorded on Bruker Avance 700, 500, 400, 300, 250, 200 spectrometers. The chemical shifts $(\delta)$ are measured according to IUPAC ${ }^{[18]}$ and expressed in ppm relative to TMS, or $\mathrm{H}_{3} \mathrm{PO}_{4}$ for ${ }^{1} \mathrm{H}$, ${ }^{13} \mathrm{C}$ and ${ }^{31} \mathrm{P}$, respectively. Coupling constants $J$ are given in Hertz [Hz] as absolute values, unless specifically stated. Where a first order analysis is appropriate, the multiplicity of the signals is indicated as $\mathrm{s}, \mathrm{d}$, or $\mathrm{m}$ for singlets, doublets, or multiplets, respectively. Aromatic carbons are indicated as $\mathrm{C}_{\mathrm{ar}}$ when not noted otherwise.

\subsection{Synthesis of Bis(2,4,6-trimethyl- benzoyl)phenylphosphane Oxide (16)}

Toluene $(100 \mathrm{ml})$ and tmeda $(4.0 \mathrm{ml}$, $26.68 \mathrm{mmol})$ are mixed and deoxygenated. $\mathrm{Na}(2.06 \mathrm{~g}, 89.52 \mathrm{mmol})$ is added and the mixture is heated for $30 \mathrm{~min}$. at $\mathrm{T}=120{ }^{\circ} \mathrm{C}$. Subsequently, $\mathrm{PhPCl}_{2}$ (4.01 g, $\left.22.41 \mathrm{mmol}\right)$ is added in one portion. The mixture turns pale yellow and a colorless precipitate starts to form. The mixture is heated $(3-5 \mathrm{~h})$ until a bright-yellow substance precipitates and the supernatant solution is colorless. To this suspension, $t$ - $\mathrm{BuOH}(3.32 \mathrm{~g}, 44.85 \mathrm{mmol}, 2$ equiv.) is added drop-wise over a period of $30 \mathrm{~min}$ at $\mathrm{T}=100{ }^{\circ} \mathrm{C}$. The yellow precipitate dissolves and the solution turns orange. After about 20 min heating at $120^{\circ} \mathrm{C}$, all sodium metal is consumed. A ${ }^{31} \mathrm{P}$ NMR spectrum indicates the presence of $>95 \% \mathrm{PhPH}_{2}$ (14) as phosphorus-containing species which is reacted with 2,4,6-trimethylbenzoylchloride 6 $(8.19 \mathrm{~g}, 44.8 \mathrm{mmol})$ such that the temperature is kept below $70^{\circ} \mathrm{C}$. Subsequently, conc. $\mathrm{H}_{2} \mathrm{SO}_{4}(1.48 \mathrm{ml}, 26.68 \mathrm{mmol})$ is slowly added at room temperature in order to neutralize tmeda. In the final step of the synthesis, 30\% aqueous hydrogen peroxide $(6.9 \mathrm{ml}, 67.5$ mmol, 3 equiv) is added whereby the temperature is kept at $45-55^{\circ} \mathrm{C}$. For work up of the reaction mixture, $\mathrm{H}_{2} \mathrm{O}(10 \mathrm{ml})$ is added, 
the organic phase is separated and washed twice with a $10 \%$ sodium hydrogencarbonate solution $(10 \mathrm{ml})$ and subsequently twice with $\mathrm{H}_{2} \mathrm{O}(10 \mathrm{ml})$. The organic phase is dried over anhydrous sodium sulfate and all volatile materials are evaporated under vacuum. The initially formed thick yellow oil starts to solidify to give a brightly yellow substance which is washed with hexanes and subsequently dried under vacuum to give crude 16 (7.9-8.4 g, 85-90\% yield, $>95 \%$ pure by ${ }^{1} \mathrm{H}$ NMR). An analytical pure sample (5.88 g $=62.7 \%$ yield) can be obtained by recrystallization from a concentrated THF solution. ${ }^{1} \mathrm{H}-\mathrm{NMR}\left(\mathrm{CDCl}_{3}\right): \delta=7.88(\mathrm{~m}, 2 \mathrm{H}, \mathrm{Ph}$ $H(2,6)), 7.53$ (m, $1 \mathrm{H}, \mathrm{Ph} H(4)), 7.43$ (m, 2 $\mathrm{H}, \mathrm{Ph} H(3,5)), 6.79\left(\mathrm{~s}, 4 \mathrm{H}\right.$, Mes $\left.H_{\mathrm{ar}}\right), 2.25$ $\left(\mathrm{s}, 6 \mathrm{H}, p-\mathrm{CH}_{3}\right), 2.15\left(\mathrm{~s}, 12 \mathrm{H}, o-\mathrm{CH}_{3}\right) .{ }^{13} \mathrm{C}-$ $\operatorname{NMR}\left(\mathrm{CDCl}_{3}\right): \delta=216.5\left(\mathrm{~d},{ }^{1} J_{\mathrm{CP}}=59.5\right.$ $\mathrm{Hz}, \mathrm{CO}), 141.4\left(\mathrm{~d},{ }^{5} J_{\mathrm{CP}}=0.8 \mathrm{~Hz}\right.$, Mes C4), $136.0\left(\mathrm{~d},{ }^{2} J_{\mathrm{CP}}=41.9 \mathrm{~Hz}\right.$, Mes C1), $133.2(\mathrm{~d}$, $\left.{ }^{4} J_{\mathrm{CP}}=3.0 \mathrm{~Hz}, \mathrm{Ph} \mathrm{C} 4\right), 132.5\left(\mathrm{~d},{ }^{2} J_{\mathrm{CP}}=8.1\right.$ $\mathrm{Hz}, \mathrm{Ph} \mathrm{C} 2,6), 129.3\left(\mathrm{~d},{ }^{4} J_{\mathrm{CP}}=0.9 \mathrm{~Hz}\right.$, Mes $\mathrm{C} 3,5), 128.8\left(\mathrm{~d},{ }^{3} J_{\mathrm{CP}} \mathrm{P}=11.2 \mathrm{~Hz}, \mathrm{Ph} \mathrm{C} 3,5\right)$, $126.2\left(\mathrm{~d},{ }^{1} J_{\mathrm{CP}}=75.7 \mathrm{~Hz}, \mathrm{Ph} \mathrm{C} 1\right), 20.0(\mathrm{~s}, o-$ $\left.\mathrm{CH}_{3}\right), 21.6\left(\mathrm{~s}, p-\mathrm{CH}_{3}\right) .{ }^{31} \mathrm{P}-\mathrm{NMR}\left(\mathrm{CDCl}_{3}\right)$ : $\delta=8.1$.

\subsection{Crystal Structure Determina- tions:}

Single crystals of $\mathbf{5}$ were obtained as yellow cuboids by slow cooling of a filtered, saturated $\left(50{ }^{\circ} \mathrm{C}\right)$ solution of $\mathrm{Na}_{2}\left(\mathrm{P}_{2} \mathrm{Ph}_{2}\right)^{[4]}$ in neat tmeda from $50{ }^{\circ} \mathrm{C}$ to room temperature. $\mathrm{M}_{\mathrm{r}}=2270.28 \mathrm{~g} \mathrm{~cm}^{-3}$; crystal size 0.31 $\times 0.28 \times 0.26 \mathrm{~mm}$; orthorhombic, space group Pbcn; $\mathrm{a}=24.37(2), \mathrm{b}=25.18(2), \mathrm{c}=$ 21.91(2) $\AA$; $\mathrm{V}=13442(19) \AA^{3} ; \mathrm{Z}=4 ; \mathrm{T}=$ $293 \mathrm{~K} ; 2 \theta_{\text {max }}=36.83^{\circ}, 4953$ independent reflections, 649 parameters, $R_{1}=0.0494$ for 2849 reflections with $\mathrm{I}>2 \sigma(\mathrm{I}), w \mathrm{R}_{2}=$ 0.1292 for all data, GOF $=0.999$. Crystals of $\mathbf{1 6}$ were obtained by slow evaporation of a hexane solution. $\mathrm{M}_{\mathrm{r}}=418.17$; crystal size $0.79 \times 0.75 \times 0.38 \mathrm{~mm}$; monoclinic, space group $\mathrm{P} 21 / \mathrm{c} ; \mathrm{a}=18.2045(3), \mathrm{b}=$ 15.0554(2), $\mathrm{c}=8.6688(1) \AA, \alpha=90.000(0)$, $\beta=103.156(4), \gamma=90.000(0) ; \mathrm{V}=2313.55$ $\AA^{3} ; \mathrm{Z}=2 ; \mathrm{T}=273 \mathrm{~K} ; 2 \theta \max =46.51^{\circ}$; 11510 independent reflections, $R_{I}=0.0446$ for 2321 reflections with $\mathrm{I}>2 \sigma(\mathrm{I})$ and $w \mathrm{R}_{2}=$ $0.1242,277$ parameters. Both crystals were measured on a 'Bruker APEX' diffractometer with $\mathrm{CCD}$ area detector using $\mathrm{Mo}_{\mathrm{K} \alpha}$ radiation $(0.71073 \AA)$. The refinement against $F^{2}$ (full matrix - least squares) was performed with SHELXTL (ver. 6.12) and SHELXL-97. Empirical absorption correction was done with SADABS (ver. 2.03). All non-hydrogen atoms were refined anisotropically. The contribution of the hydrogen atoms, in their calculated positions, was included in the refinement using a riding model. CCDC-666662 (16) and CCDC-667787 (5) contains the supplementary crystallographic data for this paper. These data can be obtained free of charge from www.ccdc. cam.ac.uk/conts/retrieving.html (or from the Cambridge Crystallographic Data Centre, 12 Union Road, Cambridge CB21EZ, UK; fax: (+44)1223-336-033; or deposit@ ccdc.cam.ac.uk)

\section{Acknowledgements}

This work is the result of a fruitful collaboration between the ETH Zürich and the Ciba Specialty Chemicals Inc which funded this research.

Received: November 29, 2007

[1] For investigations of the photophysical properties of acylphosphaneoxides see: a) T. N. Makarov, A. N. Savitsky, K. Möbius, D. Beckert, H. Paul, J. Phys. Chem. A 2005, 109, 2254; b) M. Weber, N. J. Turro, J. Phys. Chem. A 2003, 107, 3326; c) I. Gatlik, P. Rzadek, G. Gescheidt, G. Rist, B. Hellrung, J. Wirz, K. Dietliker, G. Hug, M. Kunz, J.-P. Wolf, J. Am. Chem. Soc. 1999, 121,8332 ; d) S. Jockusch, N. J. Turro, $J$. Am. Chem. Soc. 1998, 120, 11773; e) S Jockusch, I. V. Koptyug, P. F. McGarry, G. W. Sluggett, N. J. Turro, D. M. Watkins, J. Am. Chem. Soc. 1997, 119, 11495; f) U. Kolczak, G. Rist, K. Dietliker, J. Wirz, J. Am. Chem. Soc. 1996, 118, 6477; g) G. W. Sluggett, C. Turro, M.G. George, I. V. Koptyug, N. J. Turro, J. Am. Chem. Soc. 1995, 117, 5148; h) M. Kamachi, K. Kuwata, T. Sumiyoshi, W. Schnabel, J. Chem. Soc., Perkin Trans. 2 1988, 961. For reviews see: i) K. Dietliker, 'A Compilation of Photoinitiators, Commercially available for UV today', SITA Series In Surface Coatings Technologies, Edinburgh, London UK, 2002, pp. 63; j) W. Rutsch, K. Dietliker, D. Leppard, M. Koehler, L. Misev, U. Kolczak, G. Rist, Prog. Org. Coat. 1996, 27, 227 and references therein.

[2] D.G. Leppard, M. Koehler, G. Hug, PCT Int. Appl. 1996, WO 9607662 A1 19960314 CAN 125:11716 AN 1996:346073

[3] M. Scherer, D. Stein, F. Breher, J. Geier H. Schönberg, H. Grützmacher, Z. Anorg. Allg. Chem. 2005, 631, 2770.

[4] J. Geier, H. Rüegger, M. Wörle, H. Grützmacher, Angew. Chem. 2003, 115, 4081, Angew. Chem., Int. Ed. 2003, 42 , 3951 .

[5] a) J. Geier, J. Harmer, H. Grützmacher, Angew. Chem. 2004, 116, 4185; Angew. Chem., Int. Ed. 2004, 4, 4093; b) R. Wolf, A. Schisler, P. Lönnecke, C. Jones, E. HeyHawkins, Eur. J. Inorg. Chem. 2004, 16, 3277 ; c) For some structures of potassium salts, $\left[\mathrm{K}_{2}\left(\mathrm{P}_{4} \mathrm{Ph}_{4}\right)(\text { solv })_{\mathrm{x}}\right]$ see: R. Wolf, E. Hey-Hawkins, Z. Anorg. Allg. Chem. 2006, 632, 727; d) D. Stein, J. Geier, H. Schönberg, H. Grützmacher, CHIMIA 2005, 59, 119.

[6] D. Stein, A. Dransfeld, M. Flock, H. Rüegger, H. Grützmacher, Eur. J. Inorg. Chem. 2006, 4157. This reference cites also a number of earlier articles describing the reaction of $\mathrm{PhPCl}_{2}$ with reducing metals.

[7] For a computational analysis of $\mathrm{M}_{2}\left(\mathrm{P}_{4} \mathrm{R}_{4}\right)$ species see: M. Kaupp, A. Patrakov, R. Reviakine, O.L. Malkina, Chem. Eur. J. 2005, 11, 2773.
[8] For the structure of the parent dianion $\left[\mathrm{P}_{3} \mathrm{H}_{3}\right]^{2-}$ see: N. Korber, J. Aschenbrenner, J. Chem. Soc., Dalton Trans. 2001, 1165.

[9] D. B. Collum, Acc. Chem. Res. 1992, 25, 448.

[10] H. Schumann, R. Fischer, J. Organomet. Chem. 1975, 88, C13.

[11] U. Englich, K. Hassler, K. Ruhlandt-Senge, F. Uhlig, Inorg. Chem. 1998, 37, 3532.

[12] V. A. Wright, D. P. Derek, Angew. Chem., Int. Ed. 2002, 41, 2389.

[13] a) L. Brandsma, N. Gusarova, S. Arbuzova, B. Trofimov, Phosphorus, Sulfur Silicon Relat. Elem. 1996, 111, 807; b) L. Brandsma, N. K. Gusarova, A. V. Gusarov, H. D. Verkruijsse, B. A. Trofimov, Synth. Commun. 1994, 24, 3219; c) L. Brandsma, J. A. Vandoorn, R. J. Delang, N. K. Gusarova, B. A. Trofimov, Mendeleev Commun. 1995, 14; d) M. C. J. M. Van Hooijdonk, Dissertation thesis, Universität Utrecht, 1999.

[14] J.-P. Albrand, J.-B. Robert, J. Chem. Soc., Chem. Comm. 1976, 21, 876.

[15] R. Batchelor, T. Birchall, J. Am. Chem. Soc. 1982, 104, 674.

[16] J. W. Akitt, R. H. Cragg, N. N. Greenwood, Chem. Comm. 1966, 5, 135. These authors give a slightly smaller $\mathrm{PH}$ coupling, ${ }^{1} \mathrm{~J}_{\mathrm{PH}}=$ $194 \mathrm{~Hz}$.

[17] K. P. Langhans, O. Stelzer, Chem. Ber. 1987, 120, 1707

[18] a) J.-M. Huang, R.-Y. Chen, H. Chen, H.-G. Wang, Jiegou Huaxue (Chin.)(Chin. J. Struct. Chem.) 2001, 20, 349; b) W. Honggen, W. Ruji, Y. Xinkan, C. Leifeng, C. Ruyu, Jiegou Huaxue (Chin.) (Chin. J. Struct. Chem.) 1987, 6, 139; c) C. Leifeng, C. Ruyu, W. Honggen, W. Ruji, Jiegou Huaxue (Chin.) (Chin. J. Struct. Chem.) 1988, 7, 70; d) H. Nakazawa, H. Nosaka, Y. Kushi, H. Yoneda, J. Organomet. 1990 , 9, 1958; e) J. Huang, H. Chen, R. Chen, $J$. Chem. Cryst. 2001, 31, 445; f) J. Huang, $\mathrm{H}$. Chen, R. Chen, Heteroatom. Chem. 2002, 13, 63; g) J. M. Huang, R. Y. Chen, Chin. Chem. Lett. 2001, 12, 1071; h) K. A. Lyssenko, I. L. Odinets, P. V. Kazakov, M. P. Pasechnik, M. Y. Antipin, Izv. Akad. Nauk SSSR, Ser. Khim. (Russ.) (Russ. Chem. Bull.) 2005, 553; i) R. R. Naqvi, P. J. Wheatley, E. Foresti Serantoni, J. Chem. Soc. A 1971, 2751; j) I. Forristal, J. Lowman, K. Afarinkia, J. W. Steed, Cryst. Eng. Comm. 2001, 3, 53; k) D. V. Griffiths, J. E. Harris, J. R. Miller, Acta Crystallogr., Sect. C: Cryst. Struct. Commun. 1997, 53, 1462; 1) P. G. Jones, O. Kennard, Acta Crystallogr., Sect. B: Struct. Crystallogr. Cryst. Chem. 1978, 34, 2309; m) C. Ru-Yu, L. Hui-Ying, W. Hong-Gen, W. Ru-Ji, Jiegou Huaxue (Chin.) (Chin. J. Struct .Chem.) 1996, 15 , 273; n) S. Cohen, Y. Katz, R. Reich, E. Breuer, Acta Crystallogr., Sect. E: Struct. Rep. Online 2005, 61, 3008; o) C. Meier, W. H. G. Laux, J. W. Bats, Lieb. Ann. 1995, 1963; p) P. G. Jones, H. Thonnessen, private communication, 2006.

[19] R. K. Harris, E. D. Becker, S. M. Cabral de Menezes, R. Goodfellow, P. Granger, Pure Appl. Chem. 2001, 73, 1795. 